\title{
Escándalos financieros: delitos penales en el caso Odebrecht - Ecuador
}

\author{
Hidalgo Toalombo, Karen Mishell* \\ Villacís Lescano, Johanna Arecely* \\ Cocha Vásquez, Angie Somalí * \\ *Universidad de las Fuerzas Armadas-ESPE Sede Latacunga \\ Latacunga, Ecuador \\ E-mail: mishell.hidalgo96@gmail.com
}

Recibido: 09 de junio de 2020

Aprobado: 15 de junio de 2020

\section{Resumen}

La investigación se orientó a sintetizar los delitos penales que han surgido en el Ecuador tras el caso Odebrecht, mismos que son sucesos contrarios a la ley cometidos con dolo que atenta contra los principios y derechos que garantiza la ley, y son penados de acuerdo al Código Orgánico Integrado Penal del país. El estudio se encuentra estructurado en tres partes principales, en un inicio se identifica los antecedentes del caso realizados años anteriores, posteriormente una pequeña reseña de la empresa Odebrecht y sus relaciones con el Ecuador, y finalizamos con el detalle de los delitos penales que surgieron de estas relaciones. El método de investigación en este estudio parte de la investigación deductiva, ya que se iniciará de un contexto general como son los escándalos financieros, para así detallar los delitos penales que se presentaron en el caso Odebrecht-Ecuador. A su vez se utilizará la investigación cualitativa, puesto que se realizará una descripción de los delitos penales que se expusieron en dicho caso, es por ello que se recurrirá a la recolección de fuentes secundarias tales como internet, libros, leyes, tesis, artículos y páginas verídicas a los hechos como procuraduría, fiscalía, entre otras que tienen la capacidad de hacer público los hechos que se dan en el país. Con la información obtenida, concluimos que los delitos penales en este caso fueron ejecutados por varios funcionaros públicos y privados de Ecuador mediante sobornos, mismos que traen efectos negativos en la sociedad.

Palabras clave: Delitos penales, caso Odebrecht, escándalos financieros, Ecuador, funcionarios públicos. 


\title{
Financial scandals: criminal offenses in the Odebrecht case - Ecuador
}

\begin{abstract}
The investigation was aimed at synthesizing the criminal crimes that have arisen in Ecuador following the Odebrecht case, which are events contrary to the law committed with intent that violates the principles and rights guaranteed by law, and are punished according to the country's Integrated Organic Criminal Code. The study is structured in three main parts, initially identifying the background of the case from previous years, then a brief review of the Odebrecht company and its relations with Ecuador, and ending with details of the criminal crimes that arose from these relations. The method of investigation in this study is based on deductive investigation, since it will begin with a general context such as financial scandals, in order to detail the criminal crimes that occurred in the Odebrecht-Ecuador case. At the same time, qualitative research will be used, since a description will be made of the criminal offenses that were exposed in this case, which is why secondary sources such as the Internet, books, laws, theses, articles and truthful pages will be collected for the facts such as the attorney general's office, the prosecutor's office, among others that have the capacity to make public the facts that occur in the country. With the information obtained, we conclude that the criminal crimes in this case were executed by several public and private officials of Ecuador through bribes, which have negative effects on society.
\end{abstract}

Keywords: Criminal offenses, Odebrecht case, financial scandals, Ecuador, public officials.

\section{Introducción}

Odebrecht es una empresa brasileña creada en 1923, que ofrece los servicios de construcción, infraestructura, inmobiliarias, petroquímica $\mathrm{y}$ transporte y se encuentra ubicada en varios países de América, Europa, África y Asia. El escándalo empieza con una investigación en Brasil denominado Lava $\mathrm{Jato}^{1}$, en donde se había sobornado con un "modus operandi" " desde la presidencia de Norberto Odebrecht.

Existen documentos de 2001 y 2006 publicados por el Departamento de Justicia de Estado Unidos en los que se encuentran detallados los pagos que realizó la empresa a beneficiarios públicos y privados con el fin de adquirir y retener contratos en varios países del mundo. Guzmán (2018).

En 11 países de América Latina, la empresa ha pagado 788 millones de dólares sólo en temas de sobornos para ganar más de 100 proyectos de construcciones públicas y privadas. Para poder llevar a cabo los sobornos de los países involucrados, se crearon organizaciones financieras como la División de Operaciones Estructuradas para mantener la comunicación mediante correos en los que cada miembro tenía su código y contraseña. También se fundaron varias offshore en la que los países podían desviar fondos alrededor del mundo.

1. Lava Jato la inició el 17 de marzo del 2014 la Policía Federal para investigar un esquema de lavado de dinero y evasión de impuestos, y se ha convertido en la mayor ofensiva contra la corrupción de la historia de Brasil, que involucra la participación de las principales contratistas del país y Petrobras, la mayor empresa brasileña. La Nación (2016). (parr. 1).

2. El Diccionario de la Real Academia de la Lengua (DRAE) define el modus operandi como la manera especial de trabajar o actuar para alcanzar el fin propuesto. Policialmente es una expresión que define el método con el que se realiza el acto delictivo; es decir, la forma en la que un delincuente desarrolla sus actividades de acuerdo con su estilo personal. Rosewarne. G. (2001). (p. 7).

Hidalgo Toalombo Karen Mishell, Villacís Lescano Johanna Arecely, Cocha Vásquez Angie Somalí 
En Ecuador, la empresa Odebrecht fue responsable de proyectos de infraestructura como es el caso de la Hidroeléctrica San Francisco que se paralizó por encontrarse fallas en su construcción logrando con esto el cese de sus operaciones. Se debe agregar que, de las investigaciones realizadas $\mathrm{y}$ por sus propias declaraciones el director $\mathrm{y}$ superintendente de Odebrecht en Ecuador mantuvo varias reuniones con funcionarios del país como el excontralor y exvicepresidente para recibir pago de coimas por alcanzar beneficios en contrataciones públicas desde 2015 y 2017.

Tras estos hechos, en el Ecuador se actúa bajo un marco legal como es el Código Orgánico Penal en su capítulo quinto, mismo que establece las sanciones por los diferentes delitos que son fraude procesal, enriquecimiento ilícito, cohecho, concusión, lavado de activos, captación ilegal de dinero y asociación ilícita.

\section{Antecedentes}

Las investigaciones realizadas por Cevallos (2012), Tipán (2017), Solís (2017) en el Caso Odebrecht mencionan el impacto que tuvo la política exterior de Brasil y Ecuador en los conflictos de PETROBRAS Y ODEBRECHT y sus repercusiones económicas. Las naciones ejercieron una política realista, actuando fundamentalmente en pro de sus intereses particulares y el de sus empresas nacionales.

Además, este caso aparte de ser visible un acto de corrupción, levanta una denuncia y forma un escándalo político que afectó a varios gobiernos de la región. A través de la indagación de las conexiones y efectos en la relación bilateral de
Brasil y Perú en los años 2005 - 2007, con las acciones colusorias de ODEBRECHT para ganar la licitación de la Integración de la Infraestructura Regional Suramericana (IIRSA) ${ }^{3}$, usando una práctica corrupta para comprar poder y crecimiento económico. Indica que existe una relación simbiótica entre empresarios y funcionarios que puede entenderse como una burocratización corrompida, que ha nacido influenciada por la interrelación de la política de estado brasileña, el neo-desarrollismo ${ }^{4}$, y el apoyo gubernamental para que sus multinacionales inviertan en distintos países de la región, dejando una huella en la democracia y economía de éstos en el siglo XXI.

Por su parte, la Fiscalía General del Estado (2015), manifiesta que

El 21 de diciembre de 2016, el Departamento de Justicia de EE. UU. Reveló que entre el 2001 y 2016, la constructora brasileña pagó millonarios sobornos con dinero en efectivo y a través de transferencias a empresas offshore, utilizando como intermediarios a funcionarios públicos. (p.1)

Entre los países que involucran el caso Odebrecht se encuentra Ecuador, donde varios de sus funcionarios públicos se prestaron para actos de corrupción. Odebrecht ha manejado operaciones por, al menos, \$ 5.135 millones en continuadas contrataciones con siete de los diez últimos gobiernos, en los cuales, fueron presididos por León Febres-Cordero, Sixto Durán-Ballén, Fabián Alarcón, Jamil Mahuad, Gustavo Noboa, Alfredo Palacio y Rafael Correa.

3. Integración de la Infraestructura Regional Suramericana (IIRSA), es la planificación y desarrollo de proyectos para la infraestructura regional de transporte, energía y telecomunicaciones tendiente a facilitar el traslado de materias primas explotadas en diversos territorios del cono sur. Fue creada en agosto del 2000 durante la primera Cumbre Sudamericana y cuenta con el apoyo técnico y financiero del Banco Interamericano de Desarrollo (BID), la Corporación Andina de Fomento (CAF), y el Fondo Financiero para el Desarrollo de la Cuenca del Plata (FONPLATA). Observatorio Latinoamericano de Conflictos Ambientales (2017). (parr. 1).

4. Neo-desarrollismo, propone mayor intervención estatal, políticas económicas disconformes, retomar la industrialización, reducir la brecha tecnológica e imitar al Sudeste Asiático. Katz (2017). (parr.1).

REVISTA DE INVESTIGACIÓN SIGMA / Vol. 07, No 1, 2020 (pág. 50-59) 


\section{Desarrollo}

La constructora Odebrecht es una compañía familiar que remota en 1856 por un joven ingeniero alemán. Mientras que en 1923 fue fundada la constructora Emilio Odebrecht \& Cia., en donde se realizaron varios proyectos en el noreste de Brasil, pero por la crisis de la II Guerra Mundial, Emilio cedió el poder a su hijo Norberto. Pausadamente la empresa logra expandirse por la región y para 1985 sus proyectos en otros países corresponden casi el $30 \%$ de los contratos en cartera de 26 países. Actualmente la empresa se ve envuelta en un gran escándalo de corrupción en Latinoamérica, puesto que se han involucrado varios presidentes y mandatarios que han sido beneficiados con sobornos. (El Comercio, 2017)

La empresa Odebrecht apareció en Ecuador con un sistema de convenio enlazado a préstamos del Banco Nacional de Desarrollo Económico y Social $(\mathrm{BNDES})^{5}$, en 1985 se realizó el primer contrato, en el gobierno de León Febres-Cordero para la construcción del Trasvase a Santa Elena, desde ese momento han existido 30 contratos los cuales fueron firmados por la constructora extranjera e instituciones públicas del Ecuador.

La empresa brasileña tiene presencia en Ecuador desde hace 30 años, misma que está comprometida en la construcción de varias infraestructuras tales como la central hidroeléctrica San Francisco, la central Hidroeléctrica Manduriacu, la preparación del área donde algún día se debería construir la Refinería del Pacífico, la Ruta Viva en la capital de la república, el trasvase Daule-Vinces, el poliducto Pascuales Cuenca y la de mayor valor es la segunda fase del Metro Quito, entre otras. A su vez en el gobierno del líder de Alianza País, se desataron la mayoría de escándalos de corrupción, que empezaron con la expulsión de la empresa en el 2007. (El Telégrafo, 2017)

Además, entre 2003 y 2016 el Departamento de Justicia de los Estados Unidos menciono que Odebrecht sobornó por USD 349 millones a miembros del gobierno de Brasil, partidos políticos y ejecutivos y empleados de Petrobras. Y a su vez, desde el 2007 la organización pagó USD 33,5 millones en sobornos a funcionarios del Gobierno ecuatoriano con el fin de obtener beneficios en contrataciones públicas. (El Telégrafo, 2017)

De acuerdo con la Fiscalía General del Estado (2015), "se inició con las investigaciones previas el 22 de diciembre de 2016". (parr. 2015). Este caso presenta 600 personas involucradas, de las cuales se han realizado 8 pericias y 70 declaraciones, en donde se exigieron ayudas penales en Colombia, España, Andorra, Brasil, Estados Unidos y Suiza.

Bajo el caso Odebrecht, en el Ecuador se están investigando los siguientes delitos penales fraude procesal, enriquecimiento ilícito, concusión, lavado de activos, captación ilegal de dinero, asociación ilícita y cohecho.

\section{Fraude Procesal}

Según el COIP $(2014)^{6}$,

Se refiere a la persona que con el fin de inducir a engaño a la o al juez, en el decurso de un procedimiento civil o administrativo, antes de un procedimiento penal o durante él, oculte los instrumentos o pruebas, cambie el estado de las cosas, lugares o personas, será sancionada con pena privativa de libertad de uno a tres años (p.42)

5. El Banco Nacional de Desarrollo Económico y Social (BNDES) es el principal Agente de Desarrollo en Brasil. Desde su fundación en 1952, el BNDES desempeña un papel clave en el fomento de la expansión de la industria y la infraestructura del país. A lo largo de su historia, su actuación ha evolucionado de acuerdo a los desafíos socioeconómicos brasileños, llegando a cubrir el apoyo a la exportación, a la innovación tecnológica, al desarrollo socio ambiental sostenible y a la modernización de la gestión pública. Banco de Desarrollo de Brasil (2019). (Parr. 1)

6. Código Orgánico Integral Penal COIP, (2014).

Hidalgo Toalombo Karen Mishell, Villacís Lescano Johanna Arecely, Cocha Vásquez Angie Somalí 
En este delito se encuentra involucrado un perito, supuestamente por haber ocultado información y realizar cambios de nombre de una transcripción de audio en el caso Odebrecht que servía de evidencia para la investigación. Por esto se lo ha sentenciado a un año de prisión y el pago de una multa de cuatro salarios básicos unificados. (El Comercio, 2018)

Además, en la audiencia de juzgamiento, el fiscal Cristian Fierro mostro por lo menos 21 pruebas documentales, periciales y testimoniales, en donde se observaba que el procesado era el autor principal de dicho delito, en esas pruebas se encontraba el audio original ya que se habría adulterado en la transcripción del perito.

\section{Enriquecimiento Ilícito}

Para COIP (2014), "es cuando el patrimonio se ha incrementado con dinero, pero a sus ves también se considera este delito cuando se han cancelado deuda o extinguidas obligaciones". (p. 43).

Se presentó una investigación al exministro de telecomunicaciones, por dicho delito por un valor total de $\$ 100000$, en donde se elaboró un informe con sospechas de responsabilidad penal emitido por la Contraloría General del Estado (CGE). (Ecuavisa, 2018)

Por otra parte, existen 22 detenidos y 24 causas abiertas por asociación ilícita, captación ilegal de dinero, enriquecimiento ilícito, entre otros. A su vez el expresidente del Ecuador en el año 2017 fue el primer funcionario que se le sentencio a seis años de prisión por haber recibido $\$ 13,5$ millones por sobornos. (El Universo, 2018)

\section{Concusión}

Como manifiesta COIP (2014),

Las o los servidores públicos y las personas que actúen en virtud de una potestad estatal en alguna de las instituciones del Estado, determinadas en la Constitución de la República, sus agentes o dependientes oficiales que, abusando de su cargo o funciones, por sí o por medio de terceros, ordenen o exijan la entrega de derechos, cuotas, contribuciones, rentas, intereses, sueldos o gratificaciones no debidas, serán sancionados con pena privativa de libertad de tres a cinco años.

Si la conducta prevista en el inciso anterior se realiza mediante violencias o amenazas, la o el servidor público, será sancionado con pena privativa de libertad de cinco a siete años ( $\mathrm{p}$. 43).

\section{Según El Universo (2018),}

El fiscal general, Pául Pérez, acusa al Ex Contralor de haber "solicitado" \$10,1 millones a Odebrecht cuando era contralor, para el desvanecimiento de 34 glosas por más de $\$ 70$ millones relacionadas al proyecto San Francisco. Además, por entregar informes favorables de Contraloría para la brasileña respecto a proyectos como Refinería del Pacífico-movimiento de tierras, Poliducto Pascuales-Cuenca, Acueducto La Esperanza y Manduriacu.

El texto menciona que la Fiscalía después de nueve meses de investigación declaro como involucrado al Excontralor, en la audiencia debían intervenir 40 peritos y testigos, quien fue condenado a seis años de prisión. Mientras que, a su hijo, tenía acusaciones particulares de Procuraduría y la Corporación Eléctrica del Ecuador, ya que se rumoraba que era cómplice, de colocar dinero en las compañías Cosani, de Panamá y Plastiquim de Ecuador, simulando créditos de la empresa Venture Overseas, \$1,7 millones, parte de los recursos conseguidos a través de coimas transferidas por Klienfeld, offshore relacionada a Odebrecht, él fue condenado a tres años de prisión.

\section{Lavado de activos}

A juicio de COIP (2014), La persona que en forma directa o indirecta:

1. Tenga, adquiera, transfiera, posea, administre, utilice, mantenga, resguarde, entregue, transporte, convierta o se beneficie de cualquier manera, de activos de origen ilícito. 
2. Oculte, disimule o impida, la determinación real de la naturaleza, origen, procedencia o vinculación de activos de origen ilícito.

3. Preste su nombre o el de la sociedad o empresa, de la que sea socio o accionista, para la comisión de los delitos tipificados en este artículo.

4. Organice, gestione, asesore, participe o financie la comisión de los delitos tipificados en este artículo.

5. Realice, por sí mismo o por medio de terceros, operaciones $y$ transacciones financieras $o$ económicas, con el objetivo de dar apariencia de licitud a actividades de lavado de activos.

6. Ingrese o egrese dinero de procedencia ilícita por los pasos y puentes del país.

En la tabla 1 se presenta las sentencias por lavado de activos, establecidas en el COIP.

Según El Universo (2018),
La Fiscalía acusó en grado de autor directo del delito de lavado de activos a Édgar Arias, propietario de la empresa Diacelec y accionista mayoritario de la offshore panameña Columbia Managment Inc. Según la fiscal Proaño, ambas empresas fueron usadas para la transferencia y el movimiento de dineros llegados mediante cuatro offshore y un banco manejado por Odebrecht. (párr. 3).

La Fiscalía decide nombrar como culpable al propietario de la Empresa Diacelec, y confirmó que el monto de Lavado de Activos por estas empresas es de 14.5 millones de dólares.

A su vez, la Fiscalía General del Estado (2019), con base en los elementos de convicción presentados por la Fiscal de la Unidad Antilavado de Activos de la Fiscalía General del Estado, los empresarios y personas jurídicas de Diacelec S.A. y Conacero S.A. fueron llamadas a juicio por presuntamente perjudicar al Estado por un valor que superaría los USD. 14 millones. (párr. 1).

\section{Tabla 1}

Sanciones del lavado de activos

\begin{tabular}{|c|c|c|}
\hline & SANCIÓN & CAUSA \\
\hline \multirow{8}{*}{$\begin{array}{l}\text { PENA } \\
\text { PRIVATIVA DE } \\
\text { LIBERTAD }\end{array}$} & Uno a tres años & $\begin{array}{l}\text { El monto de los activos objeto del delito sea inferior a cien } \\
\text { salarios básicos unificados del trabajador en general. }\end{array}$ \\
\hline & $\begin{array}{l}\text { Cinco a siete } \\
\quad \text { años }\end{array}$ & $\begin{array}{l}\text { La c omisión del delito } \mathrm{n} \text { o presuponga la a sociación para } \\
\text { delinquir. }\end{array}$ \\
\hline & & $\begin{array}{l}\text { El monto de los activos objeto del delito sea igual o superior a } \\
\text { cien salarios básicos unificados del trabajador en general }\end{array}$ \\
\hline & & $\begin{array}{l}\text { La comisión del delito presuponga la asociación para delinquir, } \\
\text { sin servirse de la constitución de sociedades o empresas, o de } \\
\text { la utilización de las que se encuentren legalmente constituidas }\end{array}$ \\
\hline & Siete a diez años & $\begin{array}{l}\text { El d elito sea cometido u tilizando instituciones del sistema } \\
\text { financiero o de seguros; instituciones públicas o dignidades; o, } \\
\text { en el desempeño de cargos directivos, funciones o empleos en } \\
\text { dichos sistemas }\end{array}$ \\
\hline & & $\begin{array}{l}\text { El monto de los activos objeto del delito supere los doscientos } \\
\text { salarios básicos unificados del trabajador en general }\end{array}$ \\
\hline & Diez a trece años & $\begin{array}{l}\text { La comisión del delito presupone la asociación para delinquir } \\
\text { a través de la constitución de sociedades o empresas, o de la } \\
\text { utilización de las que se encuentren legalmente constituidas. }\end{array}$ \\
\hline & & $\begin{array}{l}\text { El delito ha sido cometido utilizando instituciones públicas, o } \\
\text { dignidades, cargos o empleos públicos }\end{array}$ \\
\hline
\end{tabular}

Fuente: Código Orgánico Integral Penal COIP, (2014)

Hidalgo Toalombo Karen Mishell, Villacís Lescano Johanna Arecely, Cocha Vásquez Angie Somalí 
En concordancia este acto ilícito ocurrió entre los años 2010 y 2016, un lapso donde un accionario y beneficiario de una compañía de Panamá habría recibido transferencias de cuentas de empresas controladas por dicha constructora, con el fin de pagos de sobornos o coimas.

Como participantes en este delito tenemos al accionista mayoritario de Diacelec que recibía dinero de la empresa offshore de Odebrecht en Panamá. Existe en su contra una sentencia condenatoria por el delito de asociación ilícita; a la gerente administrativa financiera y un accionista minoritario de la misma empresa, quienes habrían recibido a través del servicio de camiones blindados USD 288.946; y, la jefa financiera de Conacero S.A y Diacelec se habría beneficiado por los servicios antes mencionados por un valor de USD 374.596.

Diacelec S.A. registra dos cuentas ocultas en el sistema financiero nacional. La una de ahorros con USD 6'140.146 y la restante corriente con USD $17^{\prime} 874.840$.

Conacero S.A. habría recibido de Columbia Management USD 815.000

La Fiscalía del Ecuador culpo a seis personas y dos empresas por este delito.

\section{Captación ilegal de dinero}

Como expresa COIP (2014),

La persona que organice, desarrolle y promocione de forma pública o clandestina, actividades de intermediación financiera sin autorización legal, destinadas a captar ilegalmente dinero del público en forma habitual y masiva, será sancionada con pena privativa de libertad de cinco a siete años. (p. 50-51).

En este delito se involucraron dos Gerentes
Regionales de Sai Bnak quiénes desde 2012 hasta 2017 con la ayuda de pericias correspondientes y a través de informes financieros el Sai Bank registra ingresos en el sistema financiero nacional de USD $153^{\prime} 760.436$ y egresos por USD 146' 423.877 siendo en su mayoría transferencias. Uno de ellos Ubicaba clientes para que realicen pólizas de inversión a plazo fijo y de esta forma captaba dinero de manera ilegal y el otro a través de un poder otorgado por el gerente del banco antes mencionado, aperturaba cuentas de ahorros. Ambos fueron sentenciados a 9 años y 4 meses de prisión.

\section{Asociación Ilícita}

Teniendo en cuenta a COIP (2014),

Cuando dos o más personas se asocien con el fin de cometer delitos, sancionados con pena privativa de libertad de menos de cinco años, cada una de ellas será sancionada, por el solo hecho de la asociación, con pena privativa de libertad de tres a cinco años (p. 56).

Según PGE (2017) ${ }^{7}$

La asociación ilícita es un delito en contra la seguridad pública y afecta en consecuencia directamente el interés público que la Procuraduría General del Estado debe defender. En el caso puntual, el esquema de corrupción utilizado ha afectado directamente al interés público, irrogando graves perjuicios al patrimonio del Estado. Por consiguiente, en uso de las atribuciones establecidas en los artículos 237.1 de la Constitución, artículos 2 y 3 (b) y (c), 6 inciso 6 de la Ley Orgánica de la Procuraduría General del Estado, y artículos 11.1, 11.2, 441.6, 432.3, 433 y 444 del Código Orgánico Integral Penal, la Procuraduría General del Estado presentó acusación particular y solicitó se ordene la reparación integral al Estado ecuatoriano, por el monto de cuarenta millones de dólares, conforme

7. Procuraduría General del Estado (PGE)

REVISTA DE INVESTIGACIÓN SIGMA / Vol. 07, No 1, 2020 (pág. 50-59) 
los elementos de convicción recabados por la Fiscalía General del Estado y que sirven para cuantificar la reparación integral. (párr. 5).

Por otra parte, en este caso la Fiscalía investigó que la entrega de dinero por la constructora brasileña Odebrecht fue para funcionarios públicos y privados, ya que ellos se encargaron de entregar obras públicas en el proyecto Poliducto Pascuales-Cuenca.

En concordancia El Universo (2017), los involucrados por asociación ilícita son:

El ex vicepresidente de Ecuador, es vinculado por documentos que tendrían relación con temas que manejaba como vicepresidente $y$ como principal de los sectores estratégicos y que fueron hallados en computadoras y aparatos electrónicos del tío del ex vicepresidente; así como el testimonio del excolaborador del tío del ex vicepresidente en el canal Televisión Satelital.

El tío del ex vicepresidente, Según Fiscalía, en 2011 se presentó como intermediario del entonces ministro coordinador de Sectores Estratégicos, ante el apoderado de Odebrecht. Allí ellos habrían acordado el pago de un "peaje" de entre el $1 \%$ y el 1,3\% del total de todos los contratos de la empresa en el área de sectores estratégicos.

En la investigación, según el fiscal, se determinó que al ex contralor del Ecuador se lo identificaba con el código "Miami" y que, por ejemplo, se entregaron $\$ 700.000$ por la obra acueducto La Esperanza a través de Plastiquin.

Veintiún elementos de convicción para acusar al ex alcalde de Latacunga fueron presentados ayer en la audiencia preparatoria de juicio por el fiscal general, por presuntamente cometer el delito de asociación ilícita en el caso de sobornos de la empresa brasileña Odebrecht.

Con siete elementos de convicción se demostraría la participación del representante legal de la empresa Diacelec, empresa que habría servido para pago de sobornos en efectivo.
El fiscal presentó 16 elementos de convicción que demostrarían la participación de un ex empresario ecuatoriano en el delito de asociación ilícita en el caso Odebrecht. El procesado habría recibido un pago de $\$ 3,8$ millones para tramitar el proyecto hidroeléctrico Manduriacu.

Existe otro ex ejecutivo de Odebrecht en Ecuador, para el cual el fiscal señaló 16 elementos de convicción., puesto que este procesado contactaría a otro involucrado para entregarle los pliegos de contratación de la Refinería del Pacífico, ubicada en El Aromo (Manabí) y por ello pidió un pago de \$ 6 millones.

Sobre el ex gerente de Transporte de Petroecuador, el fiscal presentó 34 elementos de convicción. El exfuncionario habría solicitado, por ejemplo, a ex ejecutivos de Odebrecht el pago de $\$ 5$ millones para tramitar el poliducto Pascuales-Cuenca.

\section{Cohecho}

Según el COIP, (2018) en su artículo 280 identifica el cohecho como

Un acto de que una persona reciba o acepten, por sí o por interpuesta persona, beneficio económico indebido o de otra clase para sí o un tercero, sea para hacer, omitir, agilitar, retardar o condicionar cuestiones relativas a sus funciones, serán sancionados con pena privativa de libertad de uno a tres años.

$$
\text { El texto del El Telégrafo (2019), }
$$

En Ecuador la investigación de oficio por el delito de cohecho se inició el 22 de diciembre de 2016 por orden del entonces fiscal Galo Chiriboga. Esto porque según la revelación, entre 2007 y 2016 Odebrecht había pagado $\$ 33,5$ millones en coimas a funcionarios públicos y empresarios ecuatorianos para hacerse de contratos en obras. (Párr. 2).

Además, la primera asistencia penal para el caso se solicitó a Estados Unidos, el 29 de diciembre de 2016, y para inicios de febrero de 2017 ya Brasil 
tenía en sus manos uno similar. El 11 de mayo de ese año, Chiriboga fue reemplazado por Carlos Baca, quien obtuvo asistencia penal de Colombia, España, Andorra, Panamá, Suiza, Barbados, México y China para avanzar en las investigaciones.

El exvicepresidente después de nueve meses que fue sentenciado a seis años de cárcel por asociación ilícita, entro a investigaciones por el delito de cohecho, por ende, es la única indagación que tiene pendiente.

\section{Conclusiones}

Para concluir, Odebrecht es una red de corrupción donde intervenían funcionarios públicos como intermediarios para realizar contratos en sectores estratégicos, donde se determinaban las coimas para que a través de las offshore se puedan pagar. Hay que mencionar, que no se tiene establecido con claridad desde que se año se detallaron dichos sucesos. Por otra parte, existen empresarios y políticos que están en espera de una sentencia para declarar la culpabilidad o su inocencia. Además, varios personajes públicos se encuentran pagando una condena privativa de libertad, pero existe todavía una línea abierta de indagaciones para descubrir el total de personas involucradas en los delitos penales.

\section{Referencias bibliográficas}

Banco de Desarrollo de Brasil (2019). Disponible en https://www.bndes.gov.br/SiteBNDES/ bndes/bndes_es/Institucional/BNDES/

Cevallos, N.(2012). La influencia político-comercial en las relaciones entre Ecuador y Brasil en los casos PETROBAS y ODEBRECHT. Disponible en https://repositorio.uide.edu.ec/ bitstream/37000/316/1/T-UIDE-0295.pdf

Código Orgánico Integral Penal. (COIP). (14 de 02 de 2014). Disponible en http://www.lexis.com. ec/wp-content/uploads/2018/07/LI-CODIGOORGANICO-INTEGRAL-PENAL-COIP.pdf

Ecuavisa TV. (2018). Investigan a exministro por enriquecimiento ilícito. Disponible en https://www.ecuavisa.com/articulo/noticias/ nacional/415556-investigan-exministroenriquecimiento-ilicito

El Comercio. (2017). Los orígenes de Odebrecht, la constructora que está en el ojo del huracán. Disponible en https://expansion. $\mathrm{mx} /$ empresas/2017/02/16/los-origenes-deodebrecht-la-constructora-que-esta-en-el-ojodel-huracan

El Comercio. (2017). 10 Claves para entender el caso Odebrecht en Ecuador. Disponible en https://www.elcomercio.com/actualidad/ claves-caso-odebrecht-ecuador-sobornos.html

El Comercio (2018). Perito condenado por fraude procesal en caso Odebrecht en Ecuador. Disponible en https://www.elcomercio.com/ actualidad/perito-condenado-fraude-audiosodebrecht.html

El Telégrafo. (2017). Odebrecht planea sobre Ecuador desde el gobierno de Febres-Cordero. Disponible en https://www.eltelegrafo.com. ec/noticias/judicial/12/odebrecht-planea-sobreecuador-desde-el-gobierno-de-febres-cordero

Fiscalía General del Estado. (2015). ¿Qué es el caso Odebrecht?. Disponible en http://micrositio. fiscalia.gob.ec/

El Universo. (2018). Defensa de Jorge Glas visita al ex vicepresidente en la cárcel, a un año de estar detenido por delito de asociación ilícita. Disponible en https://www.eluniverso.com/ noticias/2018/10/02/nota/6981947/jorge-glasespera-que-casacion-se-disponga-nulidad-susentencia

El Universo. (2018). La corrupción de Odebrecht, una telaraña extendida por la región. Disponible en https://www.eluniverso.com/ noticias/2018/12/07/nota/7087140/corrupcionodebrecht-telarana-extendida-region

Guzmán, A. (2018). Estudio de caso: Odebrecht. Disponible en: https://repository.eafit.edu. 
co/bitstream/handle/10784/12940/Natalia Guzm\%C3\%A1nCasta\%C3\%B1o_2018. pdf? sequence $=2 \&$ isAllowed $=\mathrm{y}$

Katz, C. (2017). ¿Qué es el neo-desarrollismo? Disponible en http://www.rebelion.org/noticia. php?id $=187434$

La Nación. (2016). ¿Qué es la Operación Lava Jato? Disponible en https://www.nacion.com/ el-mundo/conflictos/que-es-la-operacion-lavajato/LC3W7IVYGBGA3PIUHCCDKOZY6I/ story/

Observatorio Latinoamericano de Conflictos Ambientales. (2017). IIRSA, La Infraestructura de la devastación. Disponible en http://olca.cl/ articulo/nota.php?id=107030

Roseguarne, G. (2001). El modus operandi y las trazas de efracción de los robos en vivienda. Disponible en file://C:/Users/Usuaria/ Downloads/Dialnet-ElModusOperandiYLasT razasDeEfraccionDeLosRobosEnVi-4722915. pdf

Solís, A. (2017). Odebrecht y la IIRSA norte y sur: un caso de corrupción y su influencia en las relaciones bilaterales con Perú en infraestructura durante los años 2005-2007. Disponible en http://tesis.pucp.edu.pe/repositorio/bitstream/ handle/20.500.12404/9209/SOLIS_LOPEZ_ AUGUSTO_PAVEL_ODEBRECHT. pdf? sequence $=1 \&$ isAllowed $=\mathrm{y}$

Tipán, D. (2017). Comunicación política: Caso Odebrecht - Ecuador explicado desde la teoría del escándalo político. Disponible en http:// dspace.udla.edu.ec/handle/33000/7675

Hidalgo Toalombo Karen Mishell, Villacís Lescano Johanna Arecely, Cocha Vásquez Angie Somalí 